FEMINISMOS CHILENOS: UNA DEMOCRATIZACIÓN ENCARNADA

\author{
Kemy Oyarzun Vaccaro
}




\section{KEMY OYARZÚN VACCARO}

Doctora en Filosofía con mención en Literatura de la Universidad de California y fundadora, en 1991, del Centro de Estudios de Género y Cultura en América Latina (CEGECAL) de la Facultad de Filosofía y Humanidades en la Universidad de Chile. Ha publicado múltiples ensayos y varios libros sobre la materia. Los dos últimos se titulan Imaginarios críticos de género en la postdictadura (Editorial Cuarto Propio) y Polifonias del cuerpo en literatura chilena contemporánea (Editorial LOM), ambos en prensa. 


\title{
FEMINISMOS CHILENOS: UNA DEMOCRATIZACIÓN ENCARNADA
}

\author{
"Yo llamo objetividad estática a aquella que niega \\ la relación entre sujeto y objeto. A esta objetividad \\ estática la veo históricamente como masculina". \\ Evelyn Fox Keller
}

RESUMEN: Este artículo se organiza en torno a las violencias simbólicas y materiales del sistema sexo-género en el marco de los procesos de democratización chilena. Se trata de una reflexión histórica sobre continuidades y diferencias del movimiento feminista en Chile a partir del MEMCH, Movimiento de Emancipación de las Mujeres Chilenas, y el Movimiento de Mayo Feminista de 2018. La idea central es evaluar las exigencias feministas en los procesos democratizadores del país. Se problematizan la subjetividad y las identidades, las ciudadanías del cuerpo, los tránsitos hacia actorías insumisas y potencialmente transformadoras del sistema neoliberal por parte del movimiento, en sus diversos imaginarios colectivos, agenciamientos y articulaciones.

\section{INTRODUCCIÓN}

Pensar en las deudas que las revueltas y las democracias tienen con los feminismos es poner en valor las insumisiones de cuerpos, culturas y territorios. En tanto movimientos sociales y políticos, los feminismos han hecho un largo trayecto en la democratización de nuestro país, así como en las grandes revueltas populares a nivel mundial. En este sentido, es difícil obviar las condiciones de enunciación de este ensayo: meses de paros feministas estudiantiles, inéditas marchas a favor de la educación gratuita, "no sexista y disidente", y el aborto libre, así como contra la homofobia, la heteronormatividad y las AFP. Se trata de ciudadanías con cuerpo, que dejan atrás los imaginarios cosificadores de las mujeres y el género femenino, propios de nuestra modernidad neocolonial y de concepciones binarias excluyentes de cuerpo o alma, sexo o erotismo, masculino o femenino. Sobre todo,

1. Evelyn Fox Keller, pp.126-127. 
se reafirma aquí una simbólica que asume la historicidad, la performatividad o la democratización como procesos en construcción y dialogismo. Nuestro Mayo Feminista ha saludado la memoria, de modo que el movimiento "Ni una menos", decididamente autónomo, resignifica el "nunca más en Chile" de la posdictadura crítica, acentuando cuatro derechos internacionalmente consagrados a las mujeres: a la libertad y a la igualdad, a la seguridad personal y a una vida libre de tratos crueles, inhumanos o degradantes (Villegas, 2018).

En el contexto de igualdad y diferencias resalta la noción de democratización impulsada por M.A. Garretón porque enfatiza la concepción dinámica y constructiva de la democracia por parte de movimientos ciudadanos, en este caso, el movimiento feminista (Garretón, 1999). Los feminismos han asumido movimientos plurales de mujeres, movimientos por la igualdad y las diferencias, pero también ciudadanías feministas decoloniales de igualdad en las diferencias. Se trata de un largo y duro proceso, dado que nuestra democracia sigue inconclusa en derechos sobre cuerpos y sexualidades, sobre casa y salud, trabajo y país. La madriguera del hogar y los espacios silentes de la escuela, la universidad o el trabajo aún se convierten en ejes de violencias, de acoso sexual y moral, a menudo en cautiverio doméstico, pero también en espacios públicos secuestrados del ejercicio ciudadano.

Hasta mayo de 2018, muchas de las subjetividades y actorías feministas postdictatoriales transitaban por espacios inciertos, en el seno de la desafección y desconfianza frente a lo político. Por eso, esta vez la insumisión puso en el tapete con renovadas fuerzas la articulación de lo privado en lo público con las denuncias y exigencias de protocolos frente a casos de acoso sexual laboral y estudiantil. Se exige una res pública con mujeres. Pese a las reformas de la Nueva Mayoría, particularmente traducidas en el fin del binominal y la consiguiente introducción de cuotas de género en las candidaturas, el voto de chilenas y chilenos en el extranjero, la agenda de probidad o la despenalización del aborto en tres causales, nuestra democracia de "baja intensidad" (Barozet, 2016, p.26) se había traducido en más profundización de expectativas que en participación real de las mujeres. En un amplio sentido, mayo de 2018 deja en evidencia las incongruencias de las lógicas consensuales que hicieron crisis al final de la Concertación para ir "tejiendo rebeldías" y actorías sociopolíticas desde las mujeres (Kirkwood, 1990). El reto ha sido doble: las reformas no pueden tener lugar sin la sociedad civil y la articulación entre sociedad civil y feminismo emerge como un deber ético-político, afirmando las diferencias en la igualdad. Mayo de 2018 ha logrado sacar lo político de las burbujas administrativas a las calles y ciudadelas universitarias, al hablar desde una símisma encarnada en sexo desde dobles experiencias: radicales feministas (género) y radicales democráticas (clase/raza). Tumulto feminista cultural y político es este, donde el sistema sexogénero se perfila con más perplejidad crítica y ahínco movimientista que en ningún otro momento de la postdictadura. 
Pero instalar identidades y actorías feministas masivamente, como ahora, ha implicado avanzar en feminismos decoloniales al problematizar marcas de sexismo, misoginia, homofobia y racismo que seguían auto/censuradas en cuerpos e imaginarios (Oyarzún, 2018). Así como los movimientos estudiantiles a partir de 2006 han venido poniendo en jaque la democracia de los consensos y el Estado subsidiario al exigir la educación como un derecho, mayo de 2018 parte por desbaratar significativos resquicios de moral victoriana explícitamente invocados a partir de la llamada "crisis moral" por la Iglesia a comienzos de la transición democrática. Judith Butler ha instado a pensar el género más como proxémica, una temporalidad social o una estilística constituida que no sólo es normativa sino que puede ser lúdica (Butler, 1998). Ineludible en este sentido referir a la acción de activistas enmascaradas cuyos pechos desnudos se enmarcaban frente a las rígidas estatuas de la Universidad Católica y de la Universidad de Chile, cuya performatividad era recepcionada con gran entusiasmo durante las intervenciones estético-políticas y las marchas, pero cuyas fotografías eran severamente censuradas por las redes sociales y los medios. A su vez, se desplegaban consignas de abierta denuncia contra el neoliberalismo o masivas exigencias de insumisión feminista, todo ello en un país que había dejado en suspenso referir a crisis estructural, hablar contra el patriarcado y el capital o que se manifestaba enfrentando, cara al público, los dispositivos de la heteronormatividad y la homofobia.

El propio concepto de género, abiertamente censurado en 1995 en los discursos de la ministra Josefina Bilbao para la Conferencia de Beijing por un Parlamento que todavía contaba con senadores designados, había quedado corto por dos razones. En primer lugar, en el plano de las ONG el concepto había sido reducido a su mínima expresión para referir casi exclusivamente a "mujeres", sin problematizarse su naturalización. En un segundo término y en un plano más conceptual, se llegó a entender que "género" excluía lo sexual en la medida en que acentuaba la desnaturalización o construcción simbólica, cuestión que irónicamente venía como anillo al dedo a la simbólica victoriana; "no hablar de sexo", a diferencia de los países centrales, es de larga duración en Chile. En tercer lugar, para algunos sectores del ámbito académico, cierto posestructuralismo inviabilizaba la noción de mujeres, descalificada como resquicio "mujeril" que de algún modo resultaba excluyente de las disidencias sexuales y signaba también una naturalización incuestionada. Distinguimos entre mujer y lo femenino en términos identitarios, dado que tanto "mujer" como "lo femenino" remiten a constructos simbólicos.

Mayo de 2018 ha insistido en hablar desde el feminismo, indistintamente de biomijeres y género, de modo que la incorporación de género y sexualidad reafirma las diferencias sexo-genéricas desde lógicas identitarias inclusivas. Los problemas del uso lingüístico refieren a quiebres de ethos, hablantes y culturas androcéntricas, 
de modo que el movimiento puso en tela de juicio los propios referentes. Basta recordar el revuelo generado en los medios cuando la propia ex Presidenta, Michelle Bachelet, utilizó el término "les chiquilles" en un saludo por Twitter, a modo de una expresión no binaria que sustituía por " $\mathrm{e}$ " las terminaciones de adjetivos, sustantivos y artículos a modo de lenguaje inclusivo ${ }^{2}$. Mujeres, disidencias, identidades queer o trans dejaron marcas indelebles en la lengua viva y cambiante. Varias veces se cuestionó desde los medios comunicacionales y la Real Academia Española de la Lengua (RAE) del periodo el uso frecuente de le o les en el lenguaje oral o la arroba en la escritura ${ }^{3}$. Esto resulta contradictorio porque Chile es uno de los países que ratificó la CETFDCM o CEDAW y forma parte de la Plataforma de Acción Mundial de Lenguaje Inclusivo, de modo que el concepto de no discriminación designe los derechos que se reconocen y a su vez el parámetro de igualdad a seguir (Fries, 2010) ${ }^{4}$. La problematización lingüística que se dio en torno a las expresiones lingüísticas de mayo de 2018 no sólo apunta a contrarrestar la discriminación de género sino a visibilizar a las mujeres como nuevas subjetividades y actoras desde un punto de vista socio-lingǘstico y político. Se intenta ir generando discusiones que incidan en lenguaje no sexista en la educación y en políticas lingüísticas pro género. Narvaja de Arnoux y Bein definen esas acciones en dos direcciones: de una parte, como "esquemas orientadores socialmente compartidos de la percepción y evaluación de los distintos fenómenos lingüísticos", y de otra, como "diseños más o menos complejos del universo social que los discursos sobre el lenguaje construyen" (1999, p.9). A partir de la comprensión de actorías y relaciones sociales de dominación en procesos de transformación se intenta incidir sobre la lengua con gestos simbólicos que permitan avanzar en la conquista de derechos. En el contexto de las relaciones de saber y poder, la lengua ha sido el reservorio de múltiples procesos, biotecnologías y disciplinas de des-subjetivación. Las exigencias de aborto libre, de una vida libre de violencias físicas y simbólicas, de educación no sexista y disidente, así como la proxémica de las acciones estético-políticas ponen en jaque las múltiples cosificaciones de las mujeres y de las marginalidades, e implican de suyo crear formas, relaciones y prácticas que fomenten las autonomías y la participación.

2. http://www.elmostrador.cl/noticias/pais/2018/06/25/les-chiquilles-el-mensaje-conlenguaje-inclusivo-que-michelle-bachelet-le-envio-a-la-ganadora-de-pasapalabra/

3. Guía de lenguaje inclusivo, Consejo Nacional de la Cultura y las Artes, Chile, 2016.

4. Fríes, Lorena (2010). Los derechos bumanos y su aporte a la igualdad de género (versión preliminar) ponencia en el Seminario Procesos Políticos e Igualdad de Género, Santiago de Chile, agosto del 2010. 


\section{LAS MUJERES TAMBIÉN TIENEN ALMA}

La teórica Gayle Rubin rompe simultáneamente con la aporía del derrocamiento de los matriarcados prehistóricos, aunque distingue en el patriarcado o sistema sexo-género hegemónico algunos rasgos estructurales de larga duración, que pese a tener incidencia particular en el capitalismo, pueden remitir a los comienzos de las sociedades de clases (Rubin, 1986). Entre ellos, distingue la tendencia de las mujeres a instituir relaciones objetales en las que son vetadas para protagonizar el lugar del sujeto, situación que ella caracteriza como "tráfico de mujeres". El tráfico de mujeres específico del capitalismo vendría a ser heredero de una larga convención en la cual las mujeres no heredan, no guían ni conversan con los dioses. En este breve recorrido sobre la subjetividad de las mujeres pasaremos por dos momentos: a) la auto exploración del alma propia por parte de algunas escritoras de comienzos del siglo XX; b) el derecho a sufragio de 1949 para las letradas; y c) la constitución de cuerpos para-sí y cuerpos-para otras como aspecto central de nuevas y modernas ciudadanías en la postdictadura, sobre todo a partir de las luchas a favor del Postinor, del aborto libre y en relación a las corporalidades problemáticas en obras literarias de Diamela Eltit, Carmen Berenguer, Eugenia Brito, Elvira Hernández, Malú Urriola, entre otras.

Muchísimo tiempo antes que Judith Butler planteara su concepción performativa del sexo-género, Flora Tristán (1803-1844) planteó las identidades como peregrinaje, como búsqueda abierta de inéditos espacios de subjetividad y relaciones en el terreno de género. Feminista, dirigente obrera y precursora en la lucha contra el patriarcado capitalista, Tristán fue tajante cuando proponía que el "nivel de civilización a que han llegado diversas sociedades humanas está en proporción directa a la independencia que gozan las mujeres", pensando desde ambas orillas de la colonialidad, en París, donde nació, y en Arequipa, de donde provenía un padre que nunca la reconoció. Agitadora social y obrera, Tristán sería reconocida por Bolívar y leída por Marx. Desde sus primeros textos denuncia la abolición del divorcio en Francia y emprende un viaje polisémico a Perú, relacionado con su herencia material y con su búsqueda identitaria. Al fracasar en el plano de los bienes patrimoniales, asume su rol de paria en territorialidad y filiación, e instala la situación

5. Según Rubin, "el patriarcado es una forma específica de dominación masculina y el uso del término debe ser confinado a los pastores nómadas del antiguo testamento (Rubin, 1986). Por su parte, Deleuze y Guattari insisten en que el patriarcado es sustituido por el Edipo en el capitalismo colonialista y neocolonialista: "decir tu padre no es tu padre, yo actuaré en su nombre, yo el Edipo colonizador” (Deleuze y Guattari, 1985, p.168). Aquí sigo refiriendo a los términos "patriarcado", "Nombre del Padre" o "sistema sexo-género hegemónico". 
de peregrina como metáfora simbólica y material. La condición de peregrinación se convierte para ella tanto en una metáfora identitaria y literaria como en una condición de enunciación. La letra de fines del XIX se producía en condiciones de inequidad para los cuerpos sometidos y normatividad por los adiestramientos letrados. Por eso las iletradas obtienen ciudadanía electoral mucho después de las letradas. Aquí en el sur, los orígenes de la Nación Estado definen como sufragantes sólo a hombres mayores de 21 que supieran leer y escribir, que tuvieran propiedad y no trabajaran como sirvientes. En Chile, las y los iletrados recién votarán en 1971, durante el gobierno de Salvador Allende. Por ello, no basta con los sufragios para comprender la dimensión y talla de nuestras revueltas.

Flora Tristán critica tempranamente el binarismo familia/nación, uno de los principales entramados de lo privado y lo público, a partir de la fuga de la casa/casta paterna, de modo que romper con el padre es romper con una identidad construida a partir del patriarcado colonial. Implícitamente, su obra plantea las tensiones entre contrato nacional y contrato sexual, en tanto da cuenta del lento proceso de incorporación de la subjetividad femenina al cuerpo de la Nación/Estado. Su trabajo gira en torno a interrogantes axiales: ¿de dónde eres? ¿En qué lengua hablas y escribes? ¿Cuál es la filiación que garantiza tu ciudadanía literaria? Nombre, lengua, genealogía, legado y herencia (paterna) quedan cuestionados junto a un cuerpo "indocumentado" por ilegítimo, situado en torno a a-filiaciones alternativas. La literatura y su activismo gremial se convierten en espacios de libertad fuera de la Ley del Padre, donde inscriben sus prácticas subalternas, relatos de una memoria clandestina que escribe desde un legado otro (Ramos, p.204).

Julieta Kirkwood fue certera al estudiar la sociedad chilena de fines del siglo XIX cuando detectó la larga duración de lo que ella calificó como "secularismo religioso", una cultura que expresa la era victoriana de los dispositivos sexuales hasta entrado el siglo XX, incluido el periodo de la dictadura cívico-militar (Kirkwood, 1990). Se trataría de una falsa laicidad que imprime al imaginario sexo-genérico un sello tendiente a satanizar y naturalizar, esencializar y universalizar los binarismos excluyentes y heteronormativos. Esa simbólica da cuenta de la exacerbada centralidad que adquiere la intervención persistente de la Iglesia y el dogmatismo cristiano a la hora de plantear la independencia del Estado respecto de la moral, los derechos civiles del cuerpo, la familia, la secularización del sujeto y las identidades de sexogénero en nuestro país. En este sentido, me parece significativo plantear un segundo momento en los tránsitos feministas de este trazado referido a la búsqueda del "alma" como cuarto propio, un repliegue de secularización social de avanzada. Para las mujeres aristocráticas de principios del siglo XX, los imaginarios del sistema sexo-género expresan un binarismo excluyente entre la autonomía masculina "para sî" y un cuerpo femenino "para otros"; un cuerpo masculino que responde al 
mandato de producción laboral y un cuerpo femenino supuestamente negado para la producción en favor de la reproducción obligada.

Aparecen a fines del siglo XIX diversas publicaciones-frecuentemente de miradas encontradas - de mujeres católicas y de mujeres espiritualistas. Entre 1885 y 1925 el país se hallaba en la era de las "leyes laicas" (Vicuña, p.186). Para 1865, un grupo de mujeres católicas fundaba un semanario denominado El eco de las señoras de Santiago en defensa ardiente del catolicismo, empoderadas para la defensa del racionalismo y el devenir religioso del país. En 1887 se fundaba la Sociedad de Obreras No. 1 de Valparaíso, presidida por Micaela Cáceres de Gamboa, cuyos estatutos proponían "fomentar la instrucción, la moralidad y el bienestar" en relación al "bien público", al prohibir explícitamente tratar cuestiones religiosas en el seno de esa institución. Entendimiento, razón y espíritu ya eran asociados a libre pensamiento y bien común. Revistas como La Familia, con sus dos ciclos, el de 1910-1928 y el de 1935-1940, expresan esas tensiones. Esta orientó su producción a las mujeres, en su mayoría de elites y letradas, y logró gran difusión dado su rol pionero en la participación y emancipación de la mujer.

A su vez, misticismo y espiritualidad se convierten en la más temprana expresión de la autonomía subjetiva en el contexto de una religiosidad laica propia de las mujeres aristocráticas de principios del siglo XX. Es el caso de Inés de Echeverría, Iris (1868-1949), quien conjuga la conflictividad interna de las mujeres en el patriarcado moderno en defensa de una concepción de vida interior, "sin cuerpo ni vestidura" para hacerla visible. Al hacerlo distinguía entre su "exterioridad" (cuerpo y vestidura), su "materia prima" (alma), su sexo (cuerpo) y su género (vestidura). En su diario, contrapuso religión y misticismo, quedando este último asociado al arte y a la creación mito poética con un sentido de espiritualidad laica. En la primera parte del siglo XX, y habiendo vivido los debates sobre las "leyes laicas", Iris encontrará que la religión organizada le secaba la imaginación, que ponía a su alma en "continuo campo de batalla" (p.17) y que estaba reñida con su nuevo modelo de feminidad. Con sorpresa, daba cuenta del atraso en la formación de las mujeres de la oligarquía del periodo; habían "aparecido unas mujeres perfectamente educadas... mientras nosotras apenas sabemos los misterios del rosario" (p.17).

¿Qué implicaciones tiene esa confesión hecha a más de cien años para la simbólica de sexo-género hoy? ¿Qué vínculos evidencia Iris entre el cuerpo, el género y la invisibilidad de las mujeres? ¿Qué nudos éticos, religiosos y políticos nos ayuda a desentrañar en nuestro imaginario de país?

A diferencia del peregrinaje simbólico y material de Flora Tristán, Iris encuentra en la espiritualidad un espacio de autonomía que le era negada en el marco victoriano de la maternidad obligatoria. Si la sexualidad como goce le estaba negada en virtud al mandato reproductivo, el erotismo y la espiritualidad se convertirán en única 
salida. Sin embargo, a pesar del cautiverio del alma y a pesar de que su escritura ha sido frecuentemente desvalorada por la crítica mascultista, el "refugio" espiritual se convertirá en espiritualidad productiva y deseante a partir de la proyección de su arte. Pese a no considerarse feminista, las mujeres de grupos católicos y seculares de la época coincidían en la noción de la opresión universal de la mujer, señalando que "saber es poder" y que el "poder es masculino" (Kirkwood, p.116).

La rebelión de Iris es reconocible precisamente en la medida en que vemos sus límites de no contaminar socialmente esa autonomía "interior". Tampoco se alteraban la división entre lo privado y lo público ni las jerarquías patriarcales. El corolario de esa híbrida secularidad se sintetizaba en aquella singular afirmación: las mujeres también tienen alma, materia de una de las conferencias de los Centros Belén de Sárraga junto a Luis Emilio Recabarren, que refería a una discusión del Concilio del Siglo VI en la que se habría discutido si la mujer tenía alma, habiéndose resuelto la duda por dos votos a favor. A su vez, el Centro de Iquique exigía que sus integrantes se comprometieran a no tener relación alguna con el clericalismo y sus instituciones, y que promovieran una educación motivada por el más alto sentimiento de libertad y de verdad (Ramos, 1986).

El Club de Señoras, fundado en 1916, por el que circuló también Iris, se distinguía por el impacto que la secularización de las relaciones sociales, incluidas la familia y el erotismo, dejaba en la búsqueda de interioridad y en la apertura a la intimidad. Por esos años, Iris se convertiría en la primera académica de la Facultad de Filosofía y Humanidades y Bellas Artes de la Universidad de Chile. A pesar de su filiación patricia, el Club de Señoras era más amplio y más abierto que el anterior Club de Lecturas. Era también muchísimo menos excluyente que su contrapartida masculina, el Club de la Unión. Más ilustrado que los norteamericanos reading clubs, en ellos se discutía un gran abanico de temáticas que iban de Shakespeare al sufragio femenino, propiciándose tanto el despertar de la "imaginación" de las mujeres como la gimnasia mental. Se abría una importante brecha en el binomio excluyente entre espíritu y religión. Se podía ser espiritualista y laica, y no adscribir a ninguna práctica de la religión organizada. Dicho de otro modo: la espiritualidad se convertía en la "única" vestidura aceptada para los cuerpos sometidos en la búsqueda de un Yo que rebasara los marcos rígidos de la familia reproductora.

Entre 1912 y 1915, con gran desparpajo contra la religión, Teresa Wilms Montt confesaba en su diario íntimo que adhería a ideas anarquistas y de la masonería. Escribía para diarios y daba conciertos; visitaba hospitales e imprentas, "acompañada de una tropa de médicos pijes y de pijes sin oficio" (Wilms Montt, 2015, p.17). La subjetividad emancipadora adquiría formas crecientemente más complejas. La respuesta conservadora no se haría esperar. En 1915 se constituía La Liga de Damas Chilenas en respuesta al avance del anticlericalismo. La Liga 
denunciaba el rol de la Iglesia como "actor de segundo orden" y anticipa lo que posteriormente sería denominada como la Teología de la Crisis Moral, para la cual la modernidad se convertirá en sinónimo de corrupción. Durante las presidencias de Montt y José Joaquín Pérez se precavía contra los embates de la anarquía a las instituciones, preconizándose la idea de la nación como "cuerpo corrompido" por el debilitamiento de los valores católicos (Vicuña, 170 y 184). Son años de difusión del positivismo, del socialismo utópico, del anarquismo. La prensa satírica ridiculiza por igual a líderes conservadores, autoridades eclesiásticas y doctrinas de la Iglesia (Vicuña, 193). La medicalización positivista va a ir asociando la "prensa impía" y la creciente secularización del registro simbólico con "gangrena mortífera", mientras el Arzobispo de Santiago, Mariano Casanova, castigará la erosión de los fundamentos del edificio social al decretar la excomunión de dos de sus representantes (Vicuña, 194). Los debates entre Ratzinger y los Teólogos de la Liberación de los '70 y la posterior Carta Pastoral del Arzobispo de Santiago, Carlos Oviedo, en 1991, Moral, Juventudy Sociedad Permisiva, revelarán cuán persistentes en el tiempo han sido las relaciones entre Iglesia, subjetividad y modernidad en nuestro país. La noción de alma para sí coincidiría con la de cuerpo para sí al incorporarse las mujeres crecientemente al ámbito laboral y político.

\section{SUFRAGISTAS LETRADAS, OBRERAS Y CAMPESINAS}

Veíamos arriba que las primeras emancipadoras de raigambre obrera, Flora Tristán y Belén de Sárraga, incorporaron equivalencias laborales y corporales junto a las demandas de autonomías identitarias. El sufragismo consolidará la trayectoria del feminismo chileno, particularmente a partir de las letradas. Los orígenes de la Nación/Estado definieron como sufragantes sólo a hombres mayores de 21, que supieran leer y escribir, que tuvieran propiedad y que no trabajaran como sirvientes. Iletrados e iletradas recién votarán en 1971 durante el gobierno de Salvador Allende.

Aquí es importante recordar la lectura de unas 880 cartas escritas por feministas memchistas de todo el país a Elena Caffarena, presidenta del Movimiento de Emancipación de la Mujer Chilena (MEMCH '35) por esos años. Son cartas que fueron rescatadas por su hija, Ana María Jiles, de un baúl mojado, antes de llegar a las manos de Elena Pedraza, Viviana Erazo y las mías, y antes que pasaran a Claudia Fedora Rojas Mira en la Biblioteca Nacional para su archivo y edición gracias al compromiso tenaz de Emma de Ramón (Claudia Rojas y Ximena Jiles, 2017). Es un epistolario de cartas breves, redactadas a máquina de escribir con teclado, que conservan borrones y tachaduras que dan cuenta de temáticas como educación femenina, lucha por el sufragio, el control de la maternidad y el aborto, leyes laborales y divorcio (Eltit, 2017). Las memchistas exigían a su presidenta letrada 
la deuda que las mujeres "instruidas" y urbanas debían tener para con las mujeres trabajadoras y campesinas de las trastierras por todo el país, porque "para eso habían estudiado”, porque la educación pública se debía devolver al Movimiento y al país. Emergían nuevas subjetividades individuales y colectivas en la medida en que las cartas mezclaban asuntos públicos y privados: "sí, habían logrado juntar ropita para los damnificados del terremoto del 39"; "les había ido bien en la actividad en solidaridad con la España del 36". Al mismo tiempo, Elena Pedraza, a su vez dirigenta de extracción obrera, cita a "Gobinda Villalobos, una obrera y memchista, esposa de un minero de la oficina salitrera Rica Aventura, pronunciaría una frase reveladora del protagonismo de las mujeres humildes en pro de la emancipación: 'La mujer empieza a vivir cuando se organiza” (Jiles, 2017, p.18). En un gesto de enorme intimidad, una de las memchistas solicitaba a Elena Caffarena que le "ayudara a encontrar a la sobrina que se había arrancado a Santiago". Según una entrevista a Elena Pedraza antes de su muerte ${ }^{6}$, Caffarena, quien trabajaba con las feministas Gabriela Mandujano y Olga Poblete, entre otras, les pedía a las letradas del Movimiento que aprendieran de las feministas populares a ser menos "mojigatas" y más desafiantes, más irreverentes e insumisas. Protagonistas y personajes de la obra de Marta Brunet, también memchista, emergen con la fuerza y desparpajo que Caffarena advertía en las feministas obreras y campesinas. A su vez, mayo de 2018 lo recoge y lo reactualiza.

Con todo, insistirá Elena Pedraza en esa entrevista, el sufragismo de fines del siglo XIX y principios del XX desarrollaría políticas coalicionales mucho más amplias, anticipando los frentes populares y los populismos democráticos.

El movimiento sufragista abrirá decididas ciudadanías electorales a las mujeres letradas entre 1949 y el golpe cívico-militar de 1973, momento en que se quiebran las ciudadanías electorales para todas y todos. Poco estudiada es la relación entre las memchistas y las integrantes de la FECHIF; en esa última participaba Amanda Labarca. Supuestamente, más que diferencias orgánico-políticas entre memchistas como Caffarena e integrantes de la FECHIF como Amanda Labarca, existiría entre ambas feministas profundas rivalidades. Lo cierto es que la llamada "Ley Maldita" de 1948 permitió al dictador González Videla cooptar la conquista de la primera ola feminista. Elena Pedraza relata las tensiones en los siguientes términos: “en 1947, se realizó el Primer Congreso de la Federación Chilena de Instituciones Femeninas (FECHIF), de la que formaba parte el MEMCH... Fue nombrada Presidenta Amanda Labarca, distinguida feminista e intelectual prominente y Elena Caffarena asumió como Vicepresidenta. El MEMCH participó con una gran delegación. A

6. Kemy Oyarzún, "Entrevista a Elena Pedraza”, Universidad de Chile, 2003, inédita. 
nivel de gobierno se estaba produciendo un quiebre en la tradición democrática. El Presidente, elegido por una coalición de partidos populares, se había comprometido a cumplir un programa ligado al pueblo. Gabriel González Videla asistió a este Congreso, invitado por Amanda Labarca, quien lamentablemente no comunicó al resto de la Asamblea de la asistencia del Presidente. La invitación era para saludar al Congreso, ese era su compromiso, pero rompió con un agresivo y amenazador discurso en contra de los comunistas... El Congreso se desordenó. Elena se levantó y se fue, la siguieron todas las memchistas. Días después, se promulgó la Ley de Defensa de la Democracia, contra el Partido Comunista y sus militantes, a la que el pueblo denominó la Ley Maldita” (Pedraza, p.21). Así, las celebraciones del sufragio femenino excluyeron a las grandes luchadoras feministas de los años '20 y '30, muchas de ellas socialistas y comunistas. En el seno de las democracias "restringidas" se entablarán una y otra vez prácticas autoritarias y excluyentes, misóginas y heteronormativas.

\section{ESE DLABLO DE CUERPO}

El péndulo de la sexualidad se condensa particularmente en la persistencia de la arcaica asociación cristiana entre carne, mujer, homosexualidad y pecado. Esta asociación incide directamente en los dispositivos de biopoder aplicados a la penalización y despenalización del aborto. Los órganos fragmentados del cuerpo, el útero, el cigoto o la genitalidad se van erigiendo en defensa a ultranza de la maternidad en la misma medida en que la mujer es des-subjetivada y la familia nuclear es elevada a categoría de paradigma ideológico. Los derechos humanos de primera generación no incluirán los derechos específicos aplicables a las mujeres sino hasta más tarde, como resultado de las llamadas dos primeras décadas de la mujer (México 1985-Beijing 1995). Se empezará a hablar entonces de derechos, referidos específicamente a las mujeres y al cuerpo como territorios de derecho.

El cuerpo del capital irá emergiendo como cuerpo naturalmente vigoroso a medida que el género instituye el cuerpo masculino en su doble utilidad: por una parte, en tanto produce rentabilidad; por otra, al plantar allí la "semilla" de la reproducción vital y social. Este imaginario configura un cuerpo físico capaz de intercambiar energía social y sexual, un cuerpo anexado al cuerpo social desde esa doble función visibilizada, normada y legitimada. El engarce particular de lo doméstico al capital hace pasar a la mujer, en cambio, por una energía exclusivamente reproductiva, invisibilizándose su productividad laboral y doméstica. La búsqueda de una inscripción social del camino entre la casa y la calle es sin duda una contribución y un encuentro con las teorías feministas. El pragmatismo se impondrá a la larga. "Invertir en las mujeres", dirá el Banco Mundial, ofrece a los responsables de las 
políticas nacionales mayores rendimientos económicos y sociales al menor de los costos: "la mujer trabaja más y gana menos" (BID, 1998).

El economicismo va implicando a nivel teórico una creciente brecha entre producción de alimentos u objetos (industria) y la producción afectivo-sexual (reproducción de la especie y reproducción de la fuerza de trabajo), aspectos de relevancia específica para el sistema sexo-género vigente. Pero también implica un desconocimiento obstinado de lo cualitativo y de la subjetividad en los pliegues del saber y del poder. A su vez, la falta de integración del pensamiento económico a los estudios culturales va llevando a desatender la dimensión comprehensiva del trabajo, reduciendo la noción de producción al rendimiento de la mercancía. Solo aquí y en este sentido, el cuerpo-energía adquiere valor "productivo" y puede ser visibilizado como bien social. Pero ese engarce es propiamente una operación de biopoder. La energía afectivo-sexual se invisibiliza como improductiva y natural, retornando al socius sólo como dispositivo de poder, estrategia de colonialidad del Yo en su doble figura docilizadora de satanización moral y medicalización. En este imaginario, un cuerpo devendrá patológico en la medida en que cese de ser objeto de rendimiento y rentabilidad. Por eso, en el caso del sexo femenino, el cuerpo no aparecerá como cuerpo para-sí. Apéndice de la producción afectivo-sexual y reproductiva, se tratará siempre de órganos transables y, por tanto, sin sujetos. La literatura sobre biopoder revela la compleja relación entre corporalidad y subjetividad.

A pesar de las resistencias, las ciudadanías de los cuerpos se han venido sumando a las ciudadanías públicas. La res pública empieza a resonar en las cosas más cotidianas. La polis se subvierte en tanto también se tensiona por dentro, desde los propios bastidores del cuerpo, la cocina y la casa, espacios que supuestamente no podrían ser incluidos en los conceptos tradicionales de ciudadanía. Tajantes oposiciones como aquellas existentes entre ethos de cuidado y ethos de justicia, supuestamente femenino y masculino respectivamente, vienen siendo aceleradamente desplazadas a los territorios semi-rurales del trabajo temporal, con la amenaza permanente de volver a precarizarse hoy en la flexibilización laboral de jóvenes y en el teletrabajo pensado para que las mujeres "no abandonen" el hogar. Los relatos de nuestro trabajo cualitativo muestran una y otra vez que los cuidados y las tareas de reproducción de la fuerza de trabajo se han ido aceleradamente privatizando, que recaen en migrantes, varones empobrecidos, mujeres, niños y niñas.

\section{ABORTO: UNA MODERNIDAD ENCARNADA}

¿Qué nuevos bríos podríamos entregarles a las ciencias de la vida, al arte, a la filosofía, al pensamiento laico para ir al encuentro de las formas y subjetividades emergentes que habitan los páramos entre la cama y la calle, entre lo íntimo y lo 
público? ¿Es posible una comunidad política que se oriente al goce pleno de la vida? ¿Cómo repensar posibilidades reales y concretas para las autonomías? ¿Es el aborto un tema ético $o$ un problema de salud? En 1935, Elena Caffarena entendió que la lucha de las mujeres era abarcadora al exigir emancipación económica, biológica y política. Esta y otras interrogantes venían a aflorar en un país que, como comunidad simbólica, se negaba hasta el segundo mandato de Michelle Bachelet a discutir la despenalización del aborto, desde que la "Ley Merino" lo criminalizó en 1989, pese a que había sido legalizado en 1931. Se ha tratado de un debate de país que implica destapar prejuicios y polaridades excluyentes. El aborto interpela principios como la equidad y los derechos y es por lo tanto un problema ético, sanitario y socioeconómico. Año tras año hemos constatado que desde el retorno a la democracia, los derechos de la mujer a decidir sobre su cuerpo se han venido esfumando tras la defensa trascendentalista de la vida del cigoto, nudo sobre el cual se proyectan ficciones biológico-religiosas que no son nunca asumidas como tales. Los seis días que dura el viaje del embrión en su desplazamiento a la Trompa de Falopio han venido tornándose notoriamente más significativos que la vida entera de las mujeres y de sus derechos. "Aquí hay una voluntad de un sector político e ideológico de frenar el tema del aborto y de luchar contra este gobierno y terminar el año con un despido de una ministra y no con la ley de la descentralización, no con la reforma laboral y no con la desgracia de la política y el dinero como es el caso Penta", sostuvo Soledad Barría, ex ministra de Salud, respecto a las declaraciones de Helia Molina, ex titular de Salud del gobierno de Michelle Bachelet. Molina había señalado el 30 de diciembre que “en todas las clínicas 'cuicas' de este país muchas de las familias más conservadoras han hecho abortar a sus hijas. Las personas con más dinero no requieren de leyes, porque tiene los recursos". Por su parte, la diputada Karol Cariola, integrante de la Comisión de Salud de la Cámara Baja, había señalado como matrona que se debe poner el aborto como tema "sanitario y de políticas públicas” (The Clinic, 2014). A las jóvenes empobrecidas de este país se les asigna una sexualidad "meramente biológica" y "natural", a expensas de la subjetividad y del derecho a decidir sobre el cuerpo. Hay que recordar que en los años '30 en Chile se logró el derecho a abortar legalmente antes que el sufragio.

La Agrupación de Mujeres por la Vida (AMV), ese amplio espectro de actoras sociales que luchó contra la dictadura militar en Chile, apuntaba con su nombre a uno de los ejes más problemáticos para las relaciones entre Iglesia y sociedad: la vida. Las defensas de la vida en las agendas de derechos humanos no han implicado posturas consensuadas respecto a los derechos sexuales y reproductivos. Por el contrario, las posturas anti-aborto, supuestamente concebidas como defensas de la vida intrauterina, jamás implicaron un posicionamiento respecto a las flagrantes violaciones de derechos humanos en las dictaduras militares del continente. En la 
postdictadura un buen número de organismos creados formalmente en defensa de la vida son grupos anti-aborto. Desde esta perspectiva, la resignificación de la vida en función de los derechos humanos que realizaron organismos como la AMV y la Agrupación de Familiares de Detenidos Desaparecidos tiene una importancia cultural no menor. Claramente, en la medida en que las mujeres se fueron involucrando en los derechos humanos, aun cuando formalmente lo hayan hecho en calidad de madres o esposas, fueron convirtiéndose en sujetos de derecho, paso que ha sido indispensable para el desarrollo de los movimientos sociales de mujeres. Las dos décadas de la mujer fueron dotando de contenidos a una agenda de derechos internacionales a favor de los derechos de mujeres y hombres hoy vigentes, convenidos por la gran mayoría de las naciones. Entre los cinco grandes grupos en los que se suele clasificar los derechos (de igualdad, de libertad, de vida, de garantías ciudadanas y políticas y de garantías socio-económicas), ninguno está pensado para restringir los comportamientos o ethos en la medida en que estos no restrinjan los espacios de otros. A diferencia de los grupos anti-aborto, promovidos al alero de las Teologías de la Crisis Moral, ninguno de los derechos de humanas y humanos hoy pretende definir normas unívocas. Antes bien, ellos presuponen la ampliación de los espacios de libertad. Se trata de acuerdos sociales que han ido avanzando en planteamientos de igualdad con equidad, justicia social y respeto a las diferencias.

Así, las agendas de derechos humanos se han propuesto evitar juicios unilaterales o normas hegemónicas impuestos desde dentro y fuera de las comunidades religiosas y políticas. Algo similar ocurre con los planteamientos de los derechos sexuales y reproductivos, cuyo dodecálogo incluye derechos a la vida, a la integridad física y mental, a no ser sometido a tortura, a la libertad y seguridad personales, a la salud física y mental y al cuidado de la salud, a la igualdad y no discriminación, a casarse y fundar una familia y a la igualdad en ella; a la libertad de pensamiento y de religión, a la privacidad y a la vida familiar, a la información y educación, a los beneficios del progreso científico y a la participación política.

La profundización de la democracia está en juego en un debate como este. La lucha por el aborto "libre, seguro y gratuito" refiere a un problema ético, jurídico $y$ sanitario porque involucra el derecho a tener derechos. La ética es la apertura a las y a los demás, a quienes miran el mundo de modo diferente y el aborto interpela ese tipo de dialogismo social. El sustento de la ley remite al piso de las diferencias y no sólo favorecer a una de las tantas miradas que sostienen chilenas y chilenos. Un país es un conjunto de comunidades de pensamiento, de moralidad y culturas. La reflexión ética abre a la posibilidad de extrañarnos y asombrarnos frente al mundo; también permite profundizar sobre nuestros actos, así como sobre la ley que los limita y circunscribe. El derecho a tener derechos es un principio motor en 
la trayectoria de los derechos humanos. La ética y la ley encarnan en comunidades interpretativas, habitando en instituciones concretas, socio-económicas, históricas y cambiantes. Es un hecho que en nuestro país las mujeres más pobres no tienen la misma posibilidad de elegir. En este sentido, la despenalización del aborto abre un debate interdisciplinario y plural de gran envergadura para la profundización de la democracia y la consolidación de una modernidad encarnada.

\section{CONCLUSIONES: HUMANAS EN CUERPOS Y DERECHOS}

La supuesta “desaparición" posmoderna de los grandes relatos ha quedado emplazada por los feminismos decoloniales en el contexto del movimiento feminista de mayo de 2018 y los movimientos sociales de la postdictadura. Pese a la espectacularidad de los monopolios mediáticos, las falacias cotidianas estructurales hacen cada vez más visibles las violencias físicas, simbólicas y económicas hacia más de la mitad de la humanidad, inconsecuencias de un modelo cuyos pactos silentes quedan a diario sobrepasados por la sociedad civil. Las prácticas feministas ponen a diario en entredicho los relatos falaces. La violencia contra las mujeres no emerge sólo como problema penal sino filosófico y político, cultural y psico-social.

Quisiera concluir con la reflexión que suscita un reciente Informe sobre violencia de género, violencia que no todas las sociedades han percibido como crimen (Villegas, 2017). Se trata de actos sobre determinados por supuestas patologías individuales en el marco de la híper medicalización del biopoder. Rita Segato insistirá en la importancia de tipificar esa violencia hacia las mujeres en contextos desvictimizantes, dado que los dispositivos jurídicos conciben esos crímenes exclusivamente como sexuales o físicos, desviados del núcleo central de la estructura patriarcal misógina (Segato, 2014). Se trata de devolver a la mujer cosificada del derecho y la medicina, de la cultura hegemónica y las culturas políticas transformadoras, la propia dimensión de "sujeto", la importancia de la autonomía sobre el sí misma, así como las autonomías de cuerpos y derechos para nosotras. Notables han sido, en ese sentido, las recomendaciones al Estado chileno por parte del Instituto Nacional de Derechos Humanos creado en 2009, el cual visibilizó como nunca antes, a más de cuarenta años de producida, la violencia sexual en el contexto de violaciones masivas y sistemáticas como la tortura, violencia sexual contra niñas y el acceso a la justicia de las mujeres indígenas en contexto de violencia de género (Fríes y Lacrampette, 2013). Una iniciativa de Michelle Bachelet, inconclusa en términos parlamentarios, deviene hoy emblemática respecto de los estándares internacionales de DD.HH. en una lúcida comprensión del derecho como herramienta de pedagogía ciudadana para la transformación de la sociedad. Cito del Artículo 2 de la misma: "La violencia contra las mujeres comprende cualquier acción u omisión (...) tenga lugar en el ámbito 
público o en el privado, basada en el género y ejercida en el marco de las relaciones de poder históricamente desiguales que emanan de los roles diferenciados asignados a hombres y mujeres, que cause o pueda causar muerte, menoscabo físico, sexual, psicológico, económico o de otra clase a las mujeres". Haber incorporado la violencia económica a ese proyecto de ley constituye en mi opinión un aporte emblemático a la comprensión de los lazos entre neoliberalismo e igualdad de género, dado que el clivaje entre producción y reproducción constituye una de las más importantes "alienaciones" del sistema de creencias, doxas y dispositivos del saber/poder de nuestros tiempos. En este sentido, Gayle Rubin tenía razón al insistir en que un sistema sexo-género es un momento de un modo de producción, pero que a su vez incluye mucho más que las relaciones de procreación (Rubin, 1986). Elena Caffarena y las memchistas denunciaron la desaparición de la asignación familiar y los sistemas de reparto de antaño como pérdidas clave de la dictadura, irresueltas durante más de dos décadas de postdictadura. Se entiende en este mismo contexto que las jóvenes feministas de hoy hayan generado desafiantes consignas sobre el mandato hegemónico de los cuidados. Los imperativos de la "maternidad moral" o el "salario familiar", conjugados durante los años republicanos del sufragismo y gravemente fracturados desde la dictadura, no han logrado re articularse durante los años neoliberales ${ }^{7}$. La monogamia heteronormativa ha quedado una y otra vez validada, contenida, consagrada y sacralizada hoy en la férrea defensa en contra del matrimonio homo y transexual. Pero la rebelión actual contra el patriarcado es sobre todo articuladora de malestares de los más diversos registros. Mayo de 2018 ha venido instalando, irreversiblemente, el derecho a identidades sexo-genéricas de múltiples cruces y posibilidades, procesos indeterminados de búsquedas, resignificación y creación. Se trata de reinsertar derechos corporeizados e identitarios lúcidamente ensamblados dentro del repertorio jurídico, político y cultural de nuestra democratización pendiente y relevar un radical imaginario en torno a la equivalencia de las y los sujetos, de sus más diversas uniones e insumisas prácticas transformadoras.

7. Dice Ximena Valdés: "Durante cerca de dos décadas de ajuste estructural (1973-1990), el principio de maternidad moral siguió formando parte del discurso institucional pero disociado del salario familiar. Las altas tasas de cesantía, sumadas a la desprotección al trabajo, van a disociar estos dos principios del orden de género industrial. A cambio, fueron focalizadas las políticas sociales en los sectores vulnerables y un dispositivo clave y universal como la Asignación Familiar perdió toda significación como apoyo económico a la familia del orden industrial". Notas sobre la metamorfosis de la familia en Chile, en "Futuro de las familias y desafíos para las políticas públicas”: Documento UMFPA y Cepal. Santiago, 22-23 de noviembre de 2007. 


\section{REFERENCIAS}

Agamben, G. [1998] 2000. Lo que queda de Auschwitz: El archivo y el testigo. Valencia: Pre-Textos.

Álvarez, A. (2000). "Belén Sárraga o la República como emblema de la fraternidad universal", en El siglo XX: balance y perspectivas. V Congreso de la Asociación de Historia Contemporánea, Valencia 2000, 219-27.

Bauman, Z. [1995] 2003. "De peregrino a turista, o una breve historia de la identidad", en H. Stuart y P. Du Gay (eds.), Cuestiones de identidad cultural, Madrid: Amorrortu Ediciones, pp. 40-68.

Bidaseca, K. (2011). Feminismos y poscolonialidad. Descolonizando el feminismo desde y en América latina, Bs. As.: Ediciones Godot.

Bourdieu, P. (2008). ¿Qué significa hablar? Economía de los intercambios lingüísticos. Madrid: Akal.

Butler, J. (1998). “Actos performativos” en Debate Feminista, Vol 18, Oct 98 pp.296314.

Deleuze y Guattari (1985). El Anti Edipo. Capitalismo y esquizofrenia. Buenos Aires: Editorial Paidós.

Denegri, F. (2003). "La insurrección comienza con una confesión”, en F. Tristán, Peregrinaciones de una paria, Lima: Fondo Editorial de la UNMSM, pp.35-69.

Eltit, Diamela (2017). "Cartas que nos llegan después de un siglo", en Epistolario emancipador del MEMCH. Catálogo histórico comentado (1935 - 1949), Santiago de Chile: Ediciones del Archivo Nacional de Chile, pp.11-13.

Fox Keller, Evelyn (1989). Reflexiones sobre género y ciencia. Valencia, España: Ediciones Alfons El Magnanim.

Fries, L. y Lacrampette, N. (2013). Feminismos, género y derecho. En: Lacrampette, N. (Ed.) Derechos Humanos y Mujeres: Teoría y Práctica. Santiago, Centro de Derechos Humanos, Santiago de Chile: Facultad de Derecho, Universidad de Chile, pp.33- 68.

Garretón, Manuel Antonio (1999). "Igualdad, ciudadanía y actores en las políticas públicas", en Sociología del desarrollo, Rolando Franco (comp.), Santiago de Chile y Montevideo: Biblioteca CEPAL, pp.172-180.

Jiles, Ximena y Rojas, Claudia (2017). Epistolario emancipador del MEMCH. Catálogo bistórico comentado (1935 - 1949), Santiago de Chile: Ediciones del Archivo Nacional de Chile. 
Narvaja de Arnoux, E. y Bein, R. (comps.) (1999). Prácticasy representaciones del lenguaje. Eudeba: Buenos Aires.

Oyarzún, Kemy (2018). "Mayo 2018: feminismos en clave decolonial”, en Faride Zerán, Mayo feminista: La rebelión contra el patriarcado, Santiago de Chile: Editorial LOM, pp.99-133.

Pedraza, Elena (2017). "Hacia una memoria feminista", en Jiles, Ximena y Rojas, Claudia (2017). Epistolario emancipador del MEMCH. Catálogo bistórico comentado (1935 - 1949), Santiago de Chile: Ediciones del Archivo Nacional de Chile.

Ramos, J., 2000. "Genealogías de la moral latinoamericanista: el cuerpo y la deuda de Flora Tristán”, en Mabel Moraña (ed.), Nuevas perspectivas desde/sobre América Latina, Santiago de Chile: Cuarto Propio, pp.185-206.

Rubin, Gayle (1986). "El tráfico de las mujeres. Notas sobre la economía política del sexo", Revista Nueva Antropología, noviembre, año/volumen VIII, número 030, México: UNAM, pp.95-145.

Sánchez, L. A., 2004. Flora Tristán, una mujer sola contra el mundo, Lima: Fondo Editorial UNMSM.

Tristán, Flora [1838] 2003. Peregrinaciones de una paria, Lima: Fondo Editorial de la UNMSM.

Valdés, Ximena (2007). "Notas sobre la metamorfosis de la familia en Chile", en Futuro de las familias y desafíos para las politicas públicas, 22-23 de noviembre de 2007. Santiago: Documento UMFPA y Cepal.

Vicuña, Manuel (2001). La Belle Epoque: Alta sociedad y mujeres de elite en el cambio de siglo. Santiago de Chile: Editorial Sudamericana.

Villegas, Myrna (2018). Violencia contra la mujer en Chile y derechos humanos, Santiago de Chile: Edición Facultad de Derecho, Universidad de Chile.

Wilms Montt, Teresa (2015). Diarios intimos. Santiago de Chile: Alquimia Ediciones. 